\title{
Obesity and breast cancer: role of inflammation and aromatase
}

\author{
Evan R Simpson ${ }^{1,2}$ and Kristy A Brown ${ }^{1,3}$ \\ ${ }^{1}$ Metabolism and Cancer Laboratory, Prince Henry's Institute of Medical Research, Clayton, Victoria 3168, Australia \\ Departments of ${ }^{2}$ Biochemistry and Molecular Biology ${ }^{3}$ Physiology, Monash University, Clayton, Victoria 3168, \\ Australia
}

Correspondence should be addressed to E R Simpson Email evan.simpson@ princehenrys.org

\begin{abstract} especially in women who are obese.

\section{Introduction}

Obesity is now recognised to be a low-grade inflammatory condition in which dysregulated metabolism plays an integral role. In this review, we will describe how inflammatory mediators regulate aromatase expression in the human breast as one mechanism whereby they increase the risk of breast cancer, especially in women who are obese. Dysregulated metabolism is also a driver of obesity-related aromatase expression in the breast, but this topic is beyond the scope of this article. However, it has recently been reviewed in some detail (Brown \& Simpson 2012, Simpson \& Brown 2013).
\end{abstract}

Obesity is now recognised to be an inflammatory condition in which dysregulated metabolism plays an integral role. Inflammatory mediators regulate aromatase expression in the human breast as one mechanism whereby they increase the risk of breast cancer,

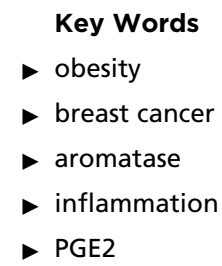

Journal of Molecular Endocrinology

(2013) 51, T51-T59

\section{The 'global pandemic' of obesity}

As we are all aware, the so-called global pandemic of obesity affects hundreds of millions of men and women worldwide. This is associated with a spectrum of co-morbidities known collectively as the metabolic syndrome, and these include type 2 diabetes, insulin resistance, cardiovascular disease and renal failure. What is less well-recognised is the fact that obesity is also associated with increased risk of a number of cancers, including those of the colon, endometrium and breast. BMI is routinely used to quantify adiposity. In the case of breast cancer, a BMI of $30 \mathrm{~kg} / \mathrm{m}^{2}$ carries with it a twofold increased risk compared with a 'normal' BMI of 24-25, and the risk continues to increase with increased obesity (Biglia et al. 2012, Garrisi et al. 2012, Kamineni et al. 2012). Breast cancer risk increases with ageing and the relationship with BMI appears to apply primarily to postmenopausal women. The expression of aromatase, the enzyme responsible for oestrogen biosynthesis, also increases with ageing in adipose tissue (reviewed in Simpson \& Brown 2013). However the molecular links in each case are not well understood.

In the case of young women, the link between BMI and breast cancer risk is more controversial (Cheraghi et al. 2012, Pierobon \& Frankenfeld 2013). This is largely due to the fact that BMI reflects overall adiposity rather than specific sites of adipose depots. More recently, waist-to-hip ratio has gained popularity as a measure of unhealthy weight gain and a study by Amadou et al. (2013) demonstrated that each 0.1 unit increase in waist-to-hip 
ratio was associated with an increased relative risk of 1.19 (95\% CI: $1.15-1.24)$ of premenopausal breast cancer irrespective of ethnicity. Additional studies, however, are required in order to determine whether waist-to-hip ratio should be used in assessing a premenopausal woman's risk of breast cancer.

\section{Aromatase}

As indicated above, aromatase is the enzyme responsible for oestrogen biosynthesis. Its single catalytic site is responsible for all three steps involved in the complex reaction leading to the formation of the phenolic A ring of oestrogens from the corresponding $\Delta^{4}$-3keto A ring of the C19 androgenic steroids, with corresponding loss of the C19 methyl group as formic acid. It is a member of the cytochrome $\mathrm{P} 450$ superfamily, which currently is known to contain over 6000 members throughout the animal and plant kingdoms. Specifically, aromatase belongs to the CYP19A1 family, of which it is the sole member. In humans, aromatase is expressed in numerous tissues: in addition to ovaries, testes and placenta, it is expressed in the mesenchymal cells of adipose tissue (but not the lipid-filled mature adipocytes), osteoblasts and chondrocytes of bone, vascular smooth muscle and endothelium, as well as numerous sites in the brain.

The human aromatase gene was cloned and characterised by us and others a number of years ago (reviewed in Simpson et al. 2002; Fig. 1). It was shown that there are nine coding exons numbered II-X, but that uniquely, upstream of the translation start-site there are a number of untranslated first exons which are spliced into the transcript in a tissue-specific fashion due to the use of a number of tissue-specific promoters. The fact that these first exons are all spliced into the transcript at a single splice junction upstream of the start of translation means that the sequence of the coding region is always the same regardless of the tissue-site of expression. Thus, expression of aromatase in the placenta is regulated by a unique distal promoter and associated first exon, called by us I.1, which is located $91 \mathrm{~kb}$ upstream of the translational start-site. The group of Carole Mendelson has shown that this promoter is regulated by the hypoxia factor hypoxiainducible factor $1 \alpha$ (HIF-1 $\alpha$ ) and estrogen-related receptor $\gamma$ (ERR $\gamma$ ) (Kumar \& Mendelson 2011). On the other hand, in adipose tissue as well as in bone another distal promoter is employed, promoter I.4, which is regulated by class 1 cytokines and tumour necrosis factor $\alpha$ (TNF $\alpha)$. Moreover, glucocorticoids are obligatorily required for this expression. In the case of the ovary and also adipose tissue, a proximal promoter is used, promoter II, so-called because no splicing is involved in its regulation of expression. However, this promoter is also associated with another promoter, I.3, which is essentially a splice-variant of promoter II. Both of these are regulated by cAMP, therefore in the ovary they are regulated by follicle-stimulating hormone (FSH), but in the case of adipose tissue, by PGE2. For the purposes of this discussion, we will consider these promoters as a single entity, promoter I.3/II. Overall, the human aromatase gene spans some $123 \mathrm{~kb}$.

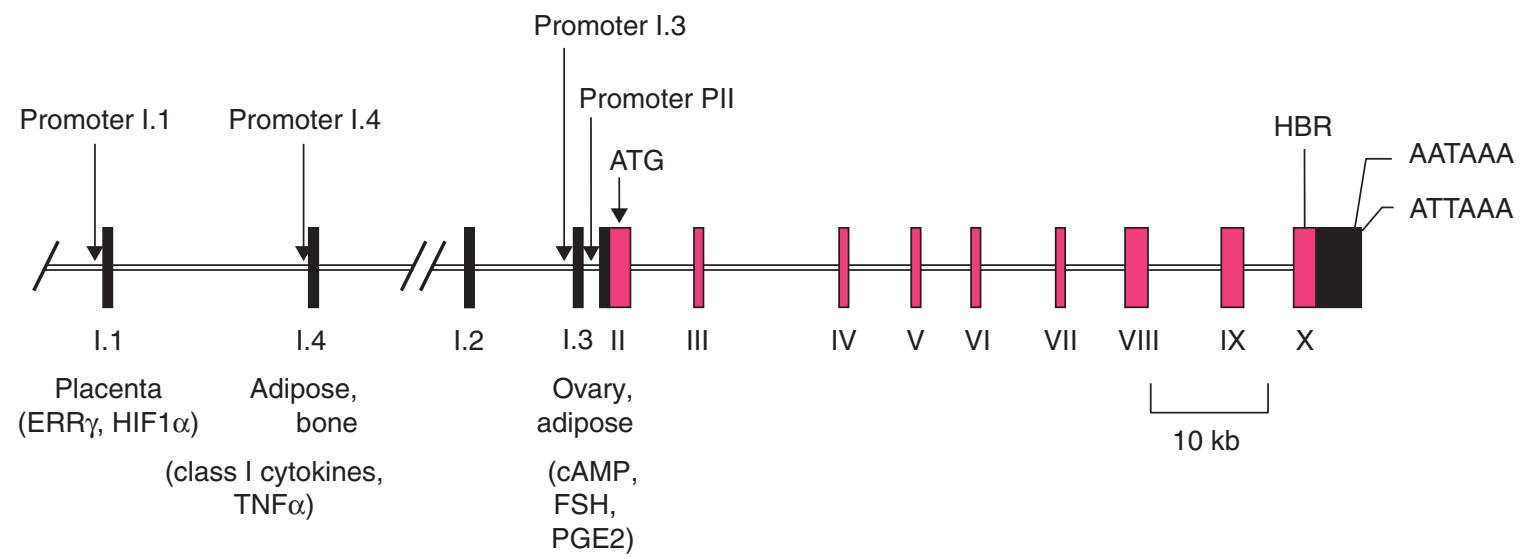

\section{Figure 1}

Diagram of the human CYP19A1 (aromatase) gene. The nine coding exons numbered II through $X$ are shown in yellow, and the untranslated first exons are shown in red together with associated promoters. Also indicated are stimulatory factors and coregulators associated with each promoter. $\mathrm{HBR}$, haeme-binding region. http://jme.endocrinology-journals.org DOI: 10.1530/JME-13-0217
() 2013 Society for Endocrinology Printed in Great Britain
Published by Bioscientifica Ltd 


\section{Oestrogen formation in the postmenopausal woman}

Although the postmenopausal ovary ceases to synthesise oestrogens, the risk of breast cancer continues to increase with age. Moreover, the majority of these cancers are oestrogen receptor (ER) positive, so what is the source of oestrogens driving ER activity? Oestrogens continue to be made in a number of extragonadal sites such as bone, brain and adipose. The latter is clearly the largest tissue involved, especially in obese individuals, and as mentioned previously, oestrogen formation and aromatase expression in adipose tissue increase with ageing (MacDonald et al. 1978, Bulun \& Simpson 1994). Breast cancer risk also increases with ageing, as well as obesity. Oestrogen levels in the plasma also increase with ageing and with BMI, and a number of epidemiological studies have shown that plasma levels are correlated with increased risk of breast cancer (Toniolo et al. 1995, Berrino et al. 1996, gens in postmenopausal women are very low compared with premenopausal ( $\sim 10$ vs $180 \mathrm{pM})$, nevertheless debate continues as to the importance of these circulating levels to drive breast cancer development.

What is seldom asked in these epidemiological studies is the source of the oestrogen in the blood of postmenopausal women - clearly the major contribution is from the adipose tissue, especially in overweight women, so our working hypothesis is indicated in Fig. 2. As mentioned previously, in adipose tissue, aromatase is expressed in the mesenchymal cells, the fibroblasts which surround the lipid-filled adipocytes, rather than in the adipocytes themselves. Aromatase in these fibroblasts utilises circulating androgens as substrate and converts them to oestrogens, in particular, oestradiol. Clearly other enzymes such as hydroxysteroid dehydrogenases and sulphatases play an important role in this process, but these will not be considered further in this review. The oestrogens can diffuse through the tissue, especially the adipose tissue of the breast, and enter the breast duct, where they will stimulate epithelial cell proliferation. Some however will enter the blood stream, circulate and then get taken up again by the adipose tissue, where they can mix with oestrogen still present there and stimulate epithelial proliferation. Thus circulating oestrogen levels will indeed be correlated with breast cancer risk, but this does not mean that they are the drivers of such risk; rather they

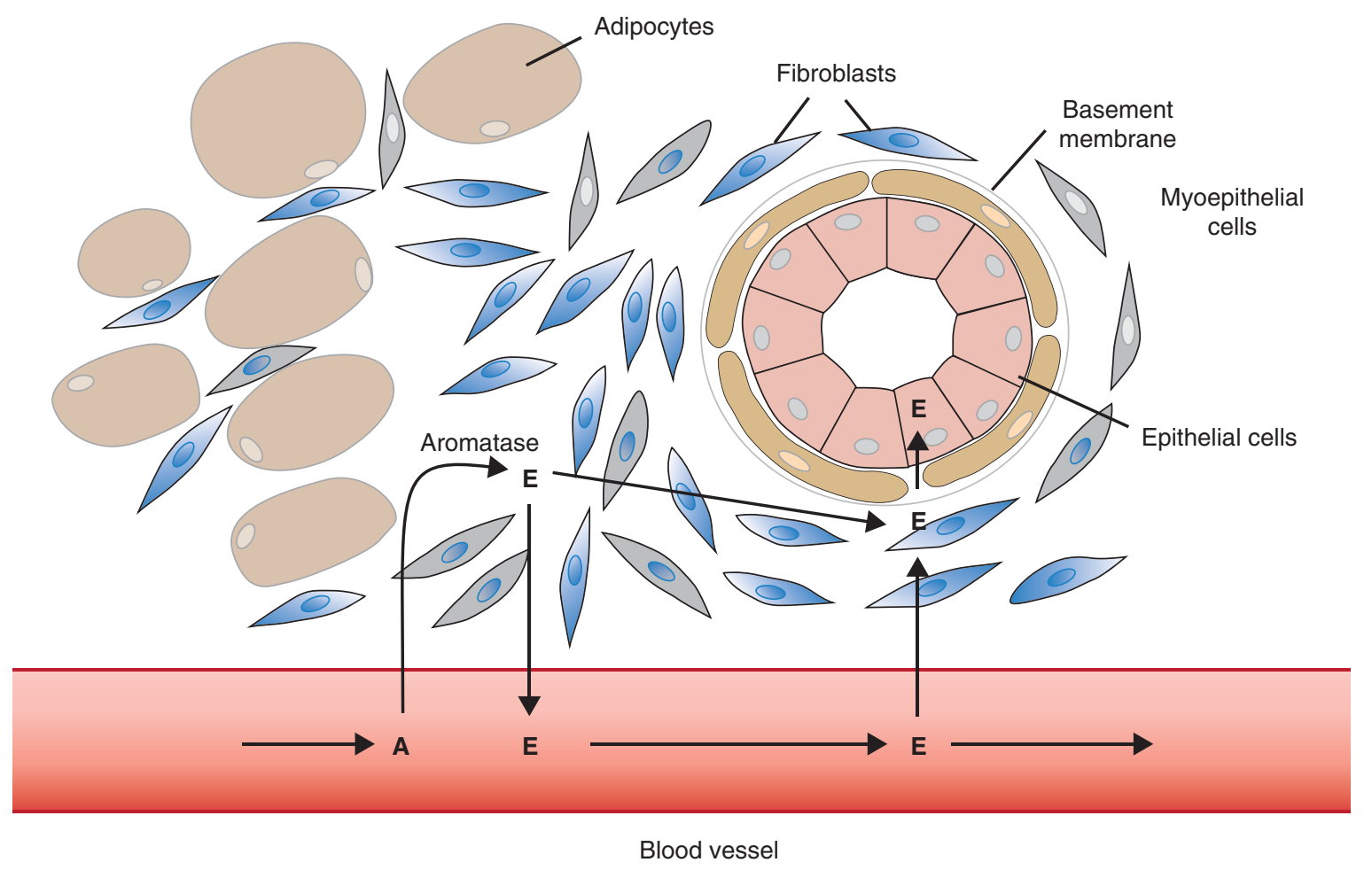

Figure 2

Diagram of a breast duct, fibroblasts and adipocytes showing the principal location of aromatase in the fibroblasts. The pathways whereby oestrogen synthesised by these fibroblasts enters the duct to stimulate epithelial proliferation are indicated.

http://jme.endocrinology-journals.org DOI: 10.1530/JME-13-0217
๑) 2013 Society for Endocrinology Printed in Great Britain
Published by Bioscientifica Ltd 
reflect the local synthesis of oestrogen within the adipose tissue, and within the breast in particular.

Evidence in support of this concept comes from a number of sources. In the first place, work was published a number of years ago by $\mathrm{O}^{\prime}$ Neill et al. (1988), in which they obtained tissue at the time of mastectomy performed for the presence of a tumour and divided it into four quadrants and determined the aromatase activity in each quadrant. Almost without exception, the tumours were located in the quadrants with the highest aromatase activity. Several years later, Bulun et al. (1993) replicated these results except that they measured aromatase expression rather than activity, and came to an identical conclusion, namely that the aromatase expression was highest in regions of the breast in which the tumour was located. This could be a consequence of two possibilities: i) if a tumour originates in a region of the breast where aromatase expression is high, then it will proliferate at a higher rate than in a region of low aromatase expression. ii) Alternatively, the tumour may secrete a factor or factors which stimulate aromatase expression locally. However, and most likely, both of these possibilities will apply. In favour of the first, Bulun also determined the ratio of stromal tissue to adipocytes in the breast quadrants, and found that the tumour was more likely to be present in a region with a high stromal cell to adipocyte ratio than a region dominated by lipid-filled adipocytes, namely a region with high aromatase expression. In favour of the second possibility was the observation that when the aromatase expression was quantified, there was seen to be a gradient of expression emanating from the region of the tumour such that expression was highest in the tumour and in the quadrant bearing the tumour; it dropped to half in quadrants of the same breast in which there was no detectable tumour present, and dropped to half again in cancer-free breast tissue.

Further support for this concept comes from the data of Sasano and colleagues in Sendai, Japan. Breast tumours are frequently surrounded by a layer of proliferating fibroblasts known as the desmoplastic reaction. But what Sasano and colleagues showed was that this layer of fibroblasts stained very densely using an aromatase antibody, indicating that these factor(s) produced by the tumour also stimulated aromatase expression in the surrounding cancer-associated fibroblasts (CAFs; Sasano $\mathrm{H}$, personal communication). In order to get a handle on what these factors might be, we sampled the CAFs and fibroblasts distal to a tumour and determined the promoter-specific expression of aromatase (Agarwal et al. 1996; Fig. 3). We found that in normal fibroblasts, the expression was quite low and was due about equally to promoter I.4 and promoters I.3/II. However, in the CAFs the large increase in expression was due largely to promoters I.3/II, whereas promoter I.4 played a lesser role. Interestingly, in a later study on a Japanese population, Irahara et al. (2006) published that promoter

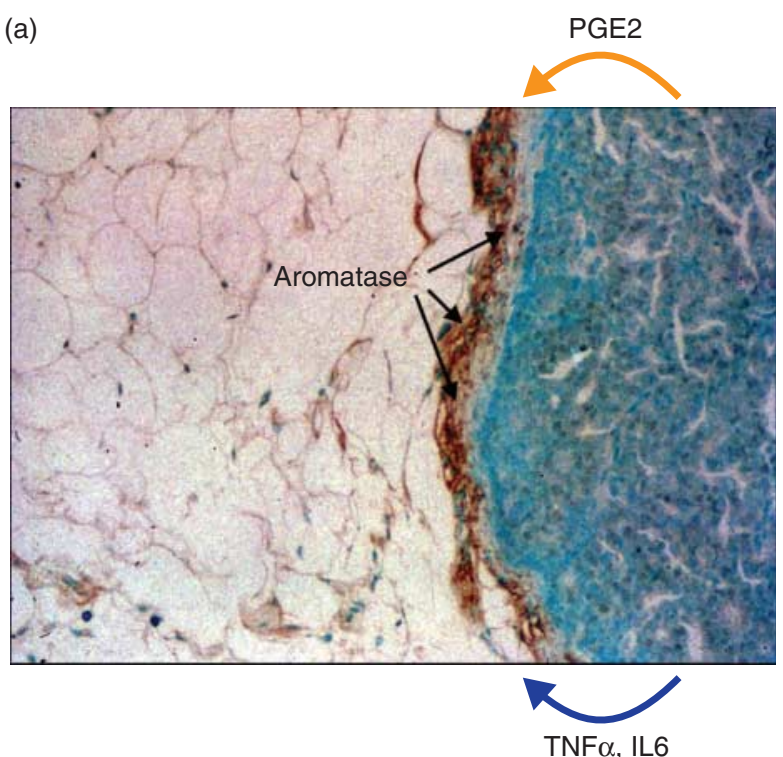

(b)

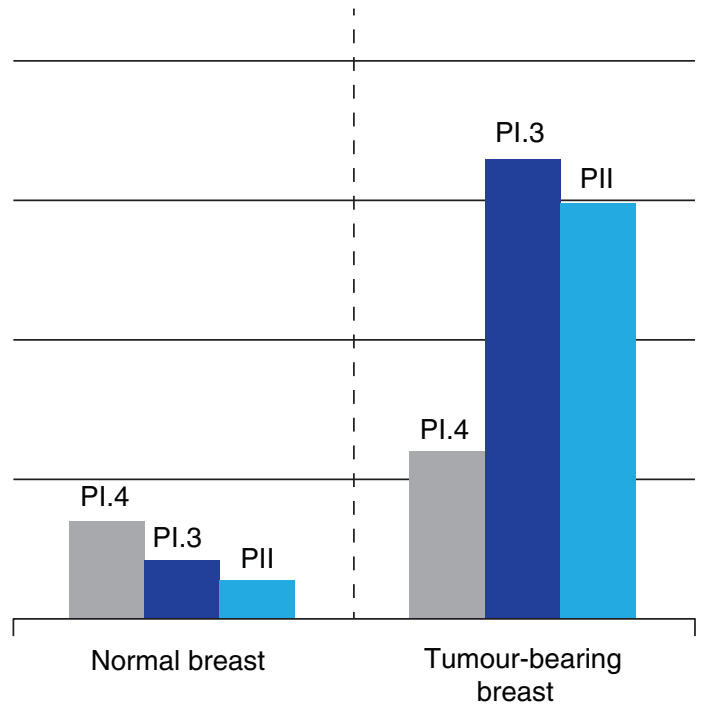

Figure 3

Diagrammatic representation of proposed epithelial-mesenchymal interactions regulating aromatase expression in the breast. Inflammatory mediators such as PGE2 produced by the tumorous epithelium stimulate the stromal fibroblasts locally to increase aromatase expression. The resulting oestrogens in turn stimulate the tumour cells to proliferate in a positive feed-on mechanism. (a) A section through breast tissue containing a large tumour (right), adipose tissue (left) and a layer of CAFs stained with aromatase antibody (Sasano $\mathrm{H}$, personal communication). (b) Promoter-specific aromatase transcripts from normal breast adipose (left) and CAFs (right).

Published by Bioscientifica Ltd 
I. 4 played a greater role in aromatase expression in CAFs than we observed in our study. Nevertheless, both of these promoters are stimulated by inflammatory mediators; in the case of promoters I.3 and II by PGE2 (Zhao et al. 1996a), and in the case of promoter I.4, by class 1 cytokines and $\mathrm{TNF} \alpha$ (Zhao et al. 1995a,b, To et al. 2013). Thus, we can envisage a scenario in which these inflammatory mediators stimulate the surrounding CAFs to express aromatase. The resulting oestrogen enters the tumour and drives proliferation with a resulting increase in the expression of these mediators. Thus, there is established a positive feed-on mechanism resulting in tumour growth, driven by mesenchymal-epithelial interactions.

\section{Regulation of aromatase expression by inflammatory mediators}

Consistent with the data presented above, aromatase expression in human breast adipose stromal (HBAS) cells is powerfully induced by PGE2 as well as by TNF $\alpha$ and class 1 cytokines such as IL6, IL11 and oncostatin M. Moreover, COX2 is expressed in many breast carcinomas where it correlates with tumour size, high grade, HER2 positivity and a worse disease-free interval. Similarly, class 1 cytokines as well as TNF $\alpha$ are expressed in breast tumours (Crichton et al. 1996, Leek et al. 1998), breast cancer cell lines and adipose tissue. We have studied the mechanism whereby PGE2 regulates aromatase promoter II in some detail (Zhao et al. 1996a), and have shown that it binds to two PGE2 receptors on the surface of breast adipose stromal cells, namely the EP1 and 2 receptors. The EP2 receptor is coupled to adenylyl cyclase, leading to the formation of cAMP and activation of PKA. This in turn phosphorylates CREB which can enter the nucleus and bind to two CREs on the aromatase promoter II. On the other hand, the EP1 receptor is coupled to phospholipase $\mathrm{C}$, leading to the formation of diacyl glycerol (DAG) and activation of PKC. PKC and phorbol esters stimulate the expression of LRH1, a monomeric orphan member of the nuclear receptor superfamily classified as NR5A2 (Zhou et al. 2005). This receptor binds to a nuclear receptor half-site downstream of the proximal CRE and is obligatorily required for aromatase expression regulated by promoter II. Among other nuclear receptor coactivators, LRH1 is activated by PGC1 $\alpha$, whose expression in turn is induced by CREB.

On the other hand, class 1 cytokines and TNF $\alpha$ regulate aromatase in HBAS cells via promoter I.4. In the case of class 1 cytokines, as illustrated in the case of IL11, these bind to a receptor which forms a heterodimer with gp160, resulting in the activation of the JAK1/STAT3 kinase pathway. The activated STAT3 in turn binds to an interferon- $\gamma$ activation site element on the promoter (Zhao et al. 1996a). On the other hand, TNF $\alpha$ appears to act via NFкB as well as an AP1 site (Zhao et al. 1995b). The early growth response genes EGF1 (GFM1) and EGF2 are downstream of $\mathrm{NF \kappa B}$ and stimulate promoter I.4 mediated aromatase expression (Zhao et al. 1996b). However, the details of this pathway have not been fully worked out. Activation of promoter I.4 by both class 1 cytokines and TNF $\alpha$ requires the presence of glucocorticoids, and these were shown to bind to a canonical GRE (Zhao et al. 1995a).

\section{Further evidence supporting the role of local oestrogen biosynthesis in the breast and breast cancer risk}

\section{Mammographic breast density}

Mammographic density is one of the strongest predictors of breast cancer risk (as much as four- to fivefold increase) and reflects the relationship between the abundance of epithelial and non-epithelial tissue, in particular fibrous tissue (reviewed in Boyd et al. 2011). However, the relationship between obesity, mammographic density and breast cancer is still open to question. The fact that obese women tend to have less dense breasts, as measured by percentage breast volume and absolute dense breast volume (Dorgan et al. 2012), is clearly an important factor complicating this issue, and is a consequence of the presence of large lipid-filled adipocytes. However, in addition there is considerable heterogeneity of dense and non-dense areas within the breast (Boyd et al. 1998) and this reflects important differences in tissue composition, in particular the presence of oestrogen-producing stromal cells. Indeed, aromatase expression is higher in dense areas of the breast compared with non-dense areas (Vachon et al. 2010). Vachon and colleagues obtained ultrasound-guided core biopsies of dense and non-dense regions of the breasts of healthy women and examined aromatase immunoreactivity using streptavidin-biotin amplification and a mouse aromatase MAB. They found an overall twofold increase in aromatase immunoreactivity in dense vs nondense regions of the breast. This was especially true in the stromal cells from the dense regions which had higher levels of aromatase immunoreactivity than epithelium (Vachon et al. 2010). Moreover, the ratio of parent oestrogen compounds (oestrone and oestradiol) to oestrogen metabolites (Fuhrman et al. 2012) is higher in dense areas of the breast compared with non-dense areas. These results

Published by Bioscientifica Ltd 
support a role of local aromatase expression in the breast as an important source of oestrogens in breast cancer risk and are consistent with the previous work of O'Neill et al. (1988) and Bulun et al. (1993). Thus it may be concluded that aromatase expression in the breast, and especially in dense stromal regions, is one mechanism whereby breast cancer risk is increased in mammographic breast density.

\section{Breast size}

If aromatase expression in the breast is a risk factor for breast cancer, then it might be expected that breast size would influence this risk, since the larger the breast size, then the larger would be the volume containing cells expressing aromatase. However, few studies have examined whether such a relationship in fact exists. One such study (Kusano et al. 2006) was a prospective study which examined the relationship between breast size and premenopausal breast cancer incidence. The conclusion was that women of healthy weight with a bra cup size D and above had a significantly higher breast cancer incidence than women with a size A or smaller. However, the association was lost in women with a higher BMI, presumably resulting from the fact that the increase in obesity itself carries an increased risk. Markkula et al. (2012) conducted a prospective cohort study in which they examined women with large breasts who had breast cancer. They showed that in women with breasts larger than $850 \mathrm{ml}$, tumour size was larger with more axillary node involvement and advanced histological grade. A confounding factor is that many women with large breasts also have a higher BMI. However, this study demonstrated that even after adjusting for BMI, breast size was still an independent predictor of lower disease-free and distant metastasis-free survival in women with ER-positive tumours.

\section{Breast inflammation and aromatase expression}

Powerful evidence in support of the relationship of breast inflammation and aromatase expression has come from a series of studies by the group of Dannenberg at Weill Cornell Medical College and Memorial Sloan Kettering (Subbaramaiah et al. 2011, 2012). These investigators examined the adipose tissue of obese vs normal weight women for inflammatory mediators and aromatase expression. In the first instance, they showed that adipocytes in the breasts of overweight women were frequently surrounded by so-called crown-like structures which were cellular and stained with CD68 antibody, indicating that they consisted of macrophages. They then went on to measure aromatase expression and activity and showed that both of these were elevated in the breasts of the obese group compared with the non-obese, as well as in the group which had macrophage infiltration. COX2 expression and protein were also elevated in these groups as were the levels of PGE2, cAMP and PKA. Increased promoter-specific aromatase expression in the women who were obese and who had macrophage infiltration was also examined and expression from both promoters I.3 and II was shown to be elevated. They also examined a marker of oestrogen action in the breasts of these women, namely the progesterone receptor, and found it also to be elevated in the breasts of the obese group and those infiltrated with macrophages (Fig. 4). The investigators concluded that 'these findings help to explain the link between obesity, low-grade chronic inflammation and breast cancer, with important clinical implications'.

Our current concepts of the relationship between obesity, aromatase and breast cancer is summarised in Fig. 5, which emphasises the role of inflammation as a link between them. The lipid-laden adipocytes in the breasts of obese women release saturated fatty acids into the blood stream. These can activate the inflammasome complexes to initiate a cascade which results in the formation of NFкB. Saturated fatty acids also activate the toll-like receptor TLR4 which also leads to increased NFкB. The adipose tissue of obese individuals is frequently hypoxic, likely due to the fact that the lipid-engorged adipocytes can hinder the entry of blood vessels into the tissue. This would result in an increase in HIF1 $\alpha$, which together with $\mathrm{NF} \kappa \mathrm{B}$ will stimulate the recruitment of macrophages to the lipid-laden adipocytes. These together with the adipocytes themselves will release inflammatory mediators such as PGE2, IL6 and TNF $\alpha$, and these in turn will stimulate the expression of aromatase in the surrounding fibroblasts.

\section{Factors which target inflammatory pathways}

As indicated above, COX2 expression is likely to be a key factor involved in tumour development in the tissues subject to chronic inflammation (van Nes et al. 2011). Furthermore, COX2 expression in human breast cancer is correlated with reduced survival, increased tumour size, high tumour grade, Her2 overexpression as well as metastases to lymph nodes and other organs. Moreover, COX2 is overexpressed in roughly $50 \%$ of breast cancer specimens inclusive of ductal carcinoma in situ (DCIS) and invasive carcinomas. As a consequence, a number of epidemiological studies including prospective, casecontrol studies as well as meta-analyses have sought to determine the efficacy of non-steroidal anti-inflammatory

Published by Bioscientifica Ltd 
(a)
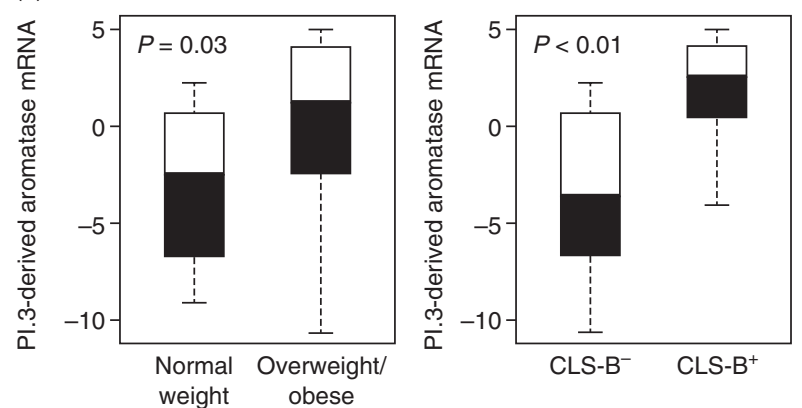

(b)
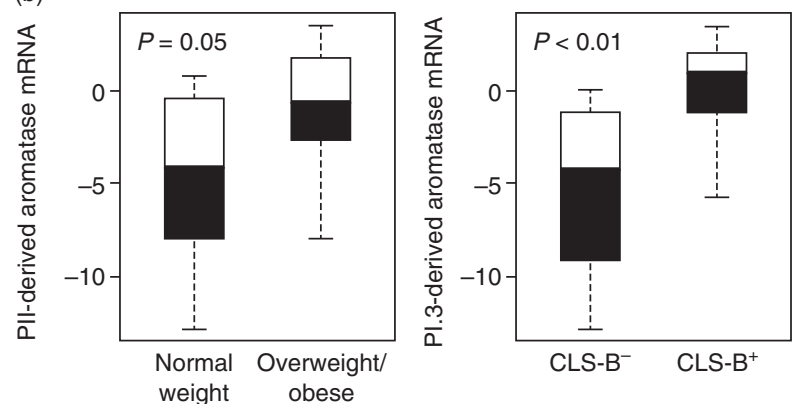

(c)

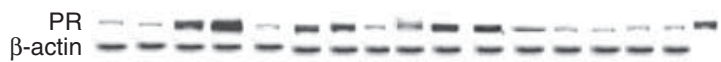

$\begin{array}{lllllllllllllllll}\text { CLS-B index } & 0 & 0 & 0.6 & 0 & 0 & 0.4 & 0.4 & 0 & 0.2 & 0.8 & 0.8 & 0.2 & 0 & 0 & 0 & 0\end{array}$
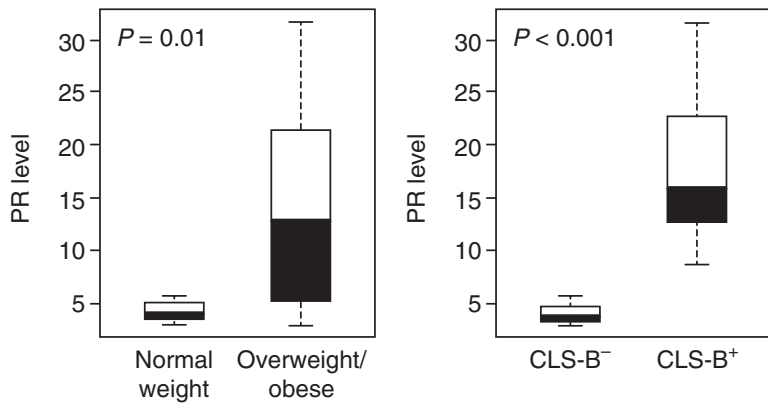

Figure 4

Expression of promoter-specific transcripts of aromatase as well as the progesterone receptor in breast tissue of overweight women, as well as those with macrophage infiltration to the adipocytes (crown-like structures, CLS)-B. PR, progesterone receptor. Adapted from Subbaramaiah K, Howe LR, Bhardwaj P, Du B, Gravaghi C, Yantiss RK, Zhou XK, Blaho VA, Hla T, Yang P, et al. Obesity is associated with inflammation and elevated aromatase expression in the mouse mammary gland, with permission from AACR. Cancer Prevention Research 20114 329-346.

drugs (NSAIDs) in terms of breast cancer prevention and treatment. The results from these studies have proven to be somewhat inconclusive (Zhang et al. 2012). While most studies have found a small benefit from the use of aspirin, results on the use of ibuprofen have been mixed with some studies showing as much as a $40 \%$ reduction in breast cancer risk (Zhang et al. 2012) and others showing no benefit. At least one case-controlled study provided data on the use of selective COX2 inhibitors for 2 years or more, namely celecoxib and rofecoxib, before these compounds were withdrawn from the market (Harris et al. 2006). In this study, 2 year use of aspirin led to a benefit odds ratio of 0.5 whereas similar use of ibuprofen led to an odds ratio of 0.4. The results obtained for the use of COX2 specific inhibitors such as rofecoxib led to a multivariate OR of 0.3. On the other hand, use of acetaminophen which has little effect on COX2 activity showed no benefit.

A number of in vitro studies have also been published examining the effect of COX2 inhibitors (reviewed in Arun \& Goss 2004) as well as inhibitors of the PGE2 receptors on both the proliferation of breast cancer cells as well as adipose stromal cells. Additionally, one study employed a syngeneic mouse breast cancer model of spontaneous lymphatic metastases (Xin et al. 2012). In general, these studies whether they utilised as endpoints cancer cell migration and invasiveness or else aromatase expression (Prosperi \& Robertson 2006) have found that mixed

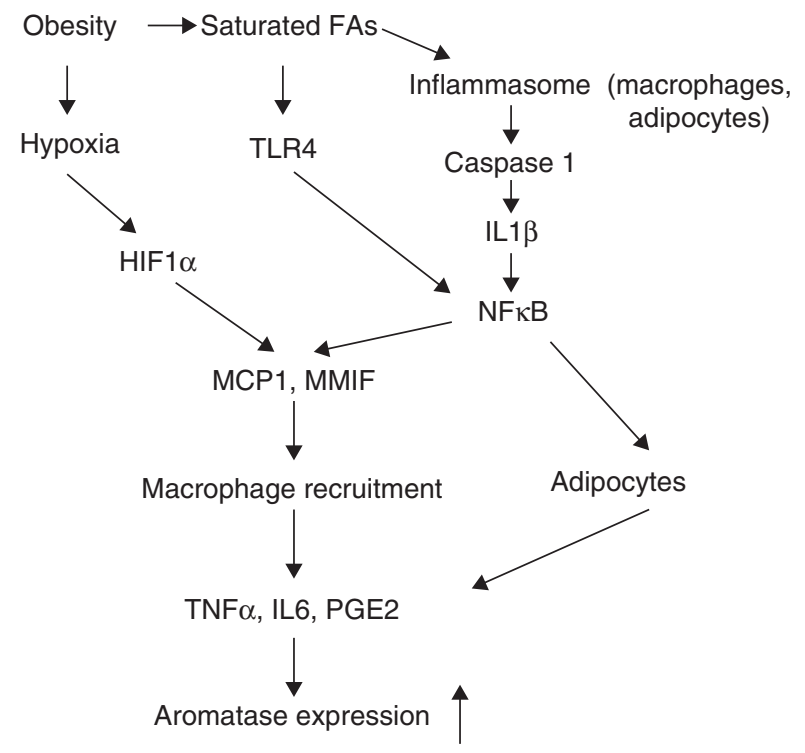

Figure 5

Current concepts of the relationship between obesity, aromatase and breast cancer emphasising the role of inflammation as a link between them. The lipid-laden adipocytes in the breasts of obese women release saturated fatty acids into the blood stream. These can activate the inflammasome complexes to initiate a cascade which results in the formation of $\mathrm{NF} \kappa \mathrm{B}$. Saturated fatty acids also activate the toll-like receptor TLR4 which also leads to increased NFKB. The adipose tissue of obese individuals is frequently hypoxic, likely due to the fact that the lipidengorged adipocytes can hinder the entry of blood vessels into the tissue. This results in an increase in hypoxia-inducible (HIF) $1 \alpha$, which together with $\mathrm{NF}_{\kappa} \mathrm{B}$ will stimulate the recruitment of macrophages to the lipid-laden adipocytes. These together with the adipocytes themselves will release inflammatory mediators such as PGE2, IL6 and TNF $\alpha$, and these in turn will stimulate the expression of aromatase in the surrounding fibroblasts.

Published by Bioscientifica Ltd 
COX1-and COX2- or COX2-specific inhibitors inhibited proliferation, migration and invasiveness as well as aromatase expression. Inhibitors of the four PGE2 receptors (Sugimoto \& Narumiya 2007) have also been examined in the context of these parameters and in general, inhibitors of the EP2 and EP4 receptors which are linked to adenylate cyclase were effective whereas those targeting the EP3 receptor were less effective or ineffective (Ma et al. 2012, Xin et al. 2012). So, although the in vitro data is strongly suggestive of the efficacy of NSAIDs in terms of therapeutic benefit, the clinical data remains somewhat inconclusive. Perhaps this will remain the case until such time as specific COX2 inhibitors are developed, which have no potentially life-threatening contraindications.

\section{Conclusions}

Inflammation has emerged as a leading player in cancer biology. Obesity provides a direct link between inflammation and dysregulated metabolism and not surprisingly therefore has an emergent role in the aetiology of numerous cancers. Although many factors play a part in this linkage, the role of obesity in postmenopausal breast cancer must also be seen in the context that oestrogen plays a dominant role in driving this disease. It would seem plausible therefore that obesity should also play a role in the regulation of oestrogen biosynthesis in adipose tissue, and this indeed is the case, both metabolically in terms of the interplay between tumour suppressors and oncogenes, but also because of the role of inflammatory mediators as the stimulators of aromatase expression, especially PGE2 produced both in the adipose itself and in the tumour. Furthermore, evidence is emerging that these factors play a role in endometrial cancer, which is also oestrogen-dependent and linked to obesity. As interest in obesity and carcinogenesis gains momentum, it is likely that we are seeing only the tip of the iceberg in terms of new knowledge and new facets of this deadly connection.

\section{Declaration of interest}

The authors declare that there is no conflict of interest that could be perceived as prejudicing the impartiality of the review.

\section{Funding}

This work was supported by NHMRC (Australia) Project Grant \# GNT1005735 to K A B and E R S, the Victorian Government, through the Victorian Cancer Agency funding of the Victorian Breast Cancer Research Consortium to E R S and $\mathrm{KA}$ B, and by the Victorian Government Operational Infrastructure Support Program. K A B is supported by an NHMRC (Australia) Career
Development Award GNT1007714. E R S is supported by an NHMRC (Australia) Senior Principal Research Fellowship GNT0550900.

\section{References}

Agarwal VR, Bulun SE, Leitch M, Rohrich R \& Simpson ER 1996 Use of alternative promoters to express the aromatase cytochrome P450 (CYP19) gene in breast adipose tissues of cancer-free and breast cancer patients. Journal of Clinical Endocrinology and Metabolism 81 3843-3849. (doi:10.1210/jc.81.11.3843)

Amadou A, Ferrari P, Muwonge R, Moskal A, Biessy C, Romieu I \& Hainaut P 2013 Overweight, obesity and risk of premenopausal breast cancer according to ethnicity: a systematic review and dose-response metaanalysis. Obesity Reviews 14 665-678. (doi:10.1111/obr.12028)

Arun B \& Goss P 2004 The role of COX-2 inhibition in breast cancer treatment and prevention. Seminars in Oncology 31 22-29. (doi:10.1053/ j.seminoncol.2004.03.042)

Berrino F, Muti P, Micheli A, Bolelli G, Krogh V, Sciajno R, Pisani P, Panico S \& Secreto G 1996 Serum sex hormone levels after menopause and subsequent breast cancer. Journal of the National Cancer Institute $\mathbf{8 8}$ 291-296. (doi:10.1093/jnci/88.5.291)

Biglia N, Peano E, Sgandurra P, Moggio G, Pecchio S, Maggiorotto F \& Sismondi P 2012 Body mass index (BMI) and breast cancer: impact on tumour histopatologic features, cancer subtypes and recurrence rate in pre and postmenopausal women. Gynecological Endocrinology 29 263-267. (doi:10.3109/09513590.2012.736559)

Boyd NF, Lockwood GA, Byng JW, Little LE, Yaffe MJ \& Tritchler DL 1998 The relationship of anthropometric measures to radiological features of the breast in premenopausal women. British Journal of Cancer $\mathbf{7 8}$ 1233-1238. (doi:10.1038/bjc.1998.660)

Boyd NF, Martin LJ, Yaffe MJ \& Minkin S 2011 Mammographic density and breast cancer risk: current understanding and future prospects. Breast Cancer Research 13 223. (doi:10.1186/bcr2942)

Brown KA \& Simpson ER 2012 Obesity and breast cancer: mechanisms and therapeutic implications. Frontiers in Bioscience 4 2515-2524. (doi:10.2741/E562)

Bulun SE \& Simpson ER 1994 Competitive reverse transcriptionpolymerase chain reaction analysis indicates that levels of aromatase cytochrome $\mathbf{P 4 5 0}$ transcripts in adipose tissue of buttocks, thighs, and abdomen of women increase with advancing age. Journal of Clinical Endocrinology and Metabolism 78 428-432. (doi:10.1210/jc.78.2.428)

Bulun SE, Price TM, Aitken J, Mahendroo MS \& Simpson ER 1993 A link between breast cancer and local estrogen biosynthesis suggested by quantification of breast adipose tissue aromatase cytochrome P450 transcripts using competitive polymerase chain reaction after reverse transcription. Journal of Clinical Endocrinology and Metabolism $\mathbf{7 7}$ 1622-1628. (doi:10.1210/jc.77.6.1622)

Cheraghi Z, Poorolajal J, Hashem T, Esmailnasab N \& Doosti Irani A 2012 Effect of body mass index on breast cancer during premenopausal and postmenopausal periods: a meta-analysis. PLoS ONE 7 e51446. (doi:10.1371/journal.pone.0051446)

Crichton MB, Nichols JE, Zhao Y, Bulun SE \& Simpson ER 1996 Expression of transcripts of interleukin- 6 and related cytokines by human breast tumors, breast cancer cells, and adipose stromal cells. Molecular and Cellular Endocrinology 118 215-220. (doi:10.1016/0303-7207(96)03761-6)

Dorgan JF, Klifa C, Shepherd JA, Egleston BL, Kwiterovich PO Jr, Himes JH, Gabriel KP, Horn LV, Snetselaar LG, Stevens VJ et al. 2012 Height, adiposity and body fat distribution and breast density in young women. Breast Cancer Research 14 R107. (doi:10.1186/bcr3228)

Fuhrman BJ, Brinton LA, Pfeiffer RM, Xu X, Veenstra TD, Teter BE, Byrne C, Dallal CM, Barba M, Muti PC et al. 2012 Estrogen metabolism and mammographic density in postmenopausal women: a cross-sectional study. Cancer Epidemiology, Biomarkers \& Prevention 21 1582-1591. (doi:10.1158/1055-9965.EPI-12-0247)

Published by Bioscientifica Ltd 
Garrisi VM, Tufaro A, Trerotoli P, Bongarzone I, Quaranta M, Ventrella V, Tommasi S, Giannelli G \& Paradiso A 2012 Body mass index and serum proteomic profile in breast cancer and healthy women: a prospective study. PLoS ONE 7 e49631. (doi:10.1371/journal.pone.0049631)

Harris RE, Beebe-Donk J \& Alshafie GA 2006 Reduction in the risk of human breast cancer by selective cyclooxygenase-2 (COX-2) inhibitors. BMC Cancer 6 27. (doi:10.1186/1471-2407-6-27)

Irahara N, Miyoshi Y, Taguchi T, Tamaki Y \& Noguchi S 2006 Quantitative analysis of aromatase mRNA expression derived from various promoters (I.4, I.3, PII and I.7) and its association with expression of TNF- $\alpha$, IL- 6 and COX-2 mRNAs in human breast cancer. International Journal of Cancer 118 1915-1921. (doi:10.1002/ijc.21562)

Kamineni A, Anderson ML, White E, Taplin SH, Porter P, Ballard-Barbash R, Malone K \& Buist DS 2012 Body mass index, tumor characteristics, and prognosis following diagnosis of early-stage breast cancer in a mammographically screened population. Cancer Causes \& Control 24 305-312. (doi:10.1007/s10552-012-0115-7)

Kumar P \& Mendelson CR 2011 Estrogen-related receptor gamma (ERRgamma) mediates oxygen-dependent induction of aromatase (CYP19) gene expression during human trophoblast differentiation Molecular Endocrinology 25 1513-1526. (doi:10.1210/me.2011-1012)

Kusano AS, Trichopoulos D, Terry KL, Chen WY, Willett WC \& Michels KB 2006 A prospective study of breast size and premenopausal breast cancer incidence. International Journal of Cancer 118 2031-2034. (doi:10.1002/ijc.21588)

Leek RD, Landers R, Fox SB, Ng F, Harris AL \& Lewis CE 1998 Association of tumour necrosis factor $\alpha$ and its receptors with thymidine phosphorylase expression in invasive breast carcinoma. British Journal of Cancer 77 2246-2251. (doi:10.1038/bjc.1998.373)

Ma X, Kundu N, Collin PD, Goloubeva O \& Fulton AM 2012 Frondoside A inhibits breast cancer metastasis and antagonizes prostaglandin $\mathrm{E}$ receptors EP4 and EP2. Breast Cancer Research and Treatment 132 1001-1008. (doi:10.1007/s10549-011-1675-z)

MacDonald PC, Edman CD, Hemsell DL, Porter JC \& Siiteri PK 1978 Effect of obesity on conversion of plasma androstenedione to estrone in postmenopausal women with and without endometrial cancer. American Journal of Obstetrics and Gynecology 130 448-455.

Markkula A, Bromee A, Henningson M, Hietala M, Ringberg A, Ingvar C, Rose C \& Jernstrom H 2012 Given breast cancer, does breast size matter? Data from a prospective breast cancer cohort Cancer Causes \& Control 23 1307-1316. (doi:10.1007/s10552-012-0008-9)

van Nes JG, de Kruijf EM, Faratian D, van de Velde CJ, Putter H, Falconer C, Smit VT, Kay C, van de Vijver MJ, Kuppen PJ et al. 2011 COX2 expression in prognosis and in prediction to endocrine therapy in early breast cancer patients. Breast Cancer Research and Treatment 125 671-685. (doi:10.1007/s10549-010-0854-7)

O'Neill JS, Elton RA \& Miller WR 1988 Aromatase activity in adipose tissue from breast quadrants: a link with tumour site. BMJ 296 741-743. (doi:10.1136/bmj.296.6624.741)

Pierobon M \& Frankenfeld CL 2013 Obesity as a risk factor for triple-negative breast cancers: a systematic review and meta-analysis. Breast Cancer Research and Treatment 137 307-314. (doi:10.1007/s10549-012-2339-3)

Prosperi JR \& Robertson FM 2006 Cyclooxygenase-2 directly regulates gene expression of P450 Cyp19 aromatase promoter regions pII, pI.3 and pI.7 and estradiol production in human breast tumor cells. Prostaglandins \& Other Lipid Mediators 81 55-70. (doi:10.1016/j.prostaglandins.2006. 07.003)

Simpson ER \& Brown KA 2013 Minireview: obesity and breast cancer: a tale of inflammation and dysregulated metabolism. Molecular Endocrinology 27 715-725. (doi:10.1210/me.2013-1011)

Simpson ER, Clyne C, Rubin G, Boon WC, Robertson K, Britt K, Speed C \& Jones M 2002 Aromatase - a brief overview. Annual Review of Physiology 64 93-127. (doi:10.1146/annurev.physiol.64.081601.142703)
Subbaramaiah K, Howe LR, Bhardwaj P, Du B, Gravaghi C, Yantiss RK, Zhou XK, Blaho VA, Hla T, Yang P et al. 2011 Obesity is associated with inflammation and elevated aromatase expression in the mouse mammary gland. Cancer Prevention Research 4 329-346. (doi:10.1158/ 1940-6207.CAPR-10-0381)

Subbaramaiah K, Morris PG, Zhou XK, Morrow M, Du B, Giri D, Kopelovich L, Hudis CA \& Dannenberg AJ 2012 Increased levels of COX-2 and prostaglandin $\mathrm{E}_{2}$ contribute to elevated aromatase expression in inflamed breast tissue of obese women. Cancer Discovery 2 356-365. (doi:10.1158/2159-8290.CD-11-0241)

Sugimoto Y \& Narumiya S 2007 Prostaglandin E receptors. Journal of Biological Chemistry 282 11613-11617. (doi:10.1074/jbc.R600038200)

Thomas HV, Key TJ, Allen DS, Moore JW, Dowsett M, Fentiman IS \& Wang DY 1997 A prospective study of endogenous serum hormone concentrations and breast cancer risk in post-menopausal women on the island of Guernsey. British Journal of Cancer 76 401-405. (doi:10.1038/bjc.1997.398)

To SQ, Knower KC \& Clyne CD 2013 NFkB and MAPK signalling pathways mediate TNF $\alpha$-induced early growth response gene transcription leading to aromatase expression. Biochemical and Biophysical Research Communications 433 96-101. (doi:10.1016/j.bbrc.2013.02.058)

Toniolo PG, Levitz M, Zeleniuch-Jacquotte A, Banerjee S, Koenig KL, Shore RE, Strax P \& Pasternack BS 1995 A prospective study of endogenous estrogens and breast cancer in postmenopausal women. Journal of the National Cancer Institute 87 190-197. (doi:10.1093/jnci/87.3.190)

Vachon CM, Sasano H, Ghosh K, Brandt KR, Watson DA, Reynolds C, Lingle WL, Goss PE, Li R, Aiyar SE et al. 2010 Aromatase immunoreactivity is increased in mammographically dense regions of the breast. Breast Cancer Research and Treatment 125 243-252. (doi:10.1007/ s10549-010-0944-6)

Xin X, Majumder M, Girish GV, Mohindra V, Maruyama T \& Lala PK 2012 Targeting COX-2 and EP4 to control tumor growth, angiogenesis, lymphangiogenesis and metastasis to the lungs and lymph nodes in a breast cancer model. Laboratory Investigation 92 1115-1128. (doi:10.1038/labinvest.2012.90)

Zhang X, Smith-Warner SA, Collins LC, Rosner B, Willett WC \& Hankinson SE 2012 Use of aspirin, other nonsteroidal anti-inflammatory drugs, and acetaminophen and postmenopausal breast cancer incidence. Journal of Clinical Oncology 30 3468-3477. (doi:10.1200/JCO.2012.42.2006)

Zhao Y, Mendelson CR \& Simpson ER 1995a Characterization of the sequences of the human CYP19 (aromatase) gene that mediate regulation by glucocorticoids in adipose stromal cells and fetal hepatocytes. Molecular Endocrinology 9 340-349. (doi:10.1210/me.9.3.340)

Zhao Y, Nichols JE, Bulun SE, Mendelson CR \& Simpson ER 1995b Aromatase P450 gene expression in human adipose tissue. Role of a $\mathrm{Jak} / \mathrm{STAT}$ pathway in regulation of the adipose-specific promoter. Journal of Biological Chemistry 270 16449-16457. (doi:10.1074/jbc.270. 27.16449)

Zhao Y, Agarwal VR, Mendelson CR \& Simpson ER 1996a Estrogen biosynthesis proximal to a breast tumor is stimulated by PGE2 via cyclic AMP, leading to activation of promoter II of the CYP19 (aromatase) gene. Endocrinology 137 5739-5742. (doi:10.1210/en.137.12.5739)

Zhao Y, Nichols JE, Valdez R, Mendelson CR \& Simpson ER 1996b Tumor necrosis factor- $\alpha$ stimulates aromatase gene expression in human adipose stromal cells through use of an activating protein-1 binding site upstream of promoter 1.4. Molecular Endocrinology 10 1350-1357. (doi:10.1210/me.10.11.1350)

Zhou J, Suzuki T, Kovacic A, Saito R, Miki Y, Ishida T, Moriya T, Simpson ER, Sasano H \& Clyne CD 2005 Interactions between prostaglandin E(2), liver receptor homologue-1, and aromatase in breast cancer. Cancer Research 65 657-663.

Received in final form 21 October 2013 Accepted 23 October 2013

Published by Bioscientifica Ltd 